\title{
Evaluation of $p$-delta effect in structural seismic response
}

\author{
Sardasht Sardar $^{1,2, *}$, and Ako Hama ${ }^{1}$ \\ ${ }^{1}$ Komar University of Science and Technology, Sulaymaniyah, Iraq \\ ${ }^{2}$ Housing Research Center, Faculty of Engineering, UPM, Malaysia
}

\begin{abstract}
Numerous recent studies have assessed the effect of P-Delta on the structures. This paper investigates the effect of P-Delta in seismic response of structures with different heights. For indicating the effect of P-Delta, nonlinear static analysis (pushover analysis) and nonlinear dynamic analysis (Time history analysis) were conducted by using finite element software. The results showing that the P-Delta has a significant impact on the structural behavior mainly on the peak amplitude of building when the height of the structures increased. In addition, comparison has been made between concrete and steel structure.
\end{abstract}

\section{Introduction}

One of the major parameters in tall building analysis is the structural height. As the height of building increases, the structure requires more attention to be given. Several studies indicated that the structural height has a significant effect on P-Delta value. The studies showed that P-Delta effect on low and medium column height is lesser than slender columns [1].

Gaiotti and Smith, (1989) proposed a method to analyze the effect of P-Delta in tall buildings. It has been shown that computing P-delta is crucial. In particular, for low structural stiffness and tall buildings [2]. It was found that ignoring the effect of P-Delta leads to a loss of $16 \%$ of load carrying capacity when the structure get subjected to repeated loading. Furthermore, the difference between static and repeated loading was 13\% of load carrying capacity due to P-Delta effect [3]. Therefore, Non-linear Dynamic Analysis can be used to determine the contribution of P-Delta in the structural analysis. Kwak et al. (2007) investigated the effect of PDelta in slender reinforced concrete columns based on the principle of the layered section method. The correlation between the influence of axial force, P-Delta effect, and the effect of vertical earthquake have been assessed. The method was successfully verified [4]. Davidson et al. (1992) indicated that the strength required to support influence of P-Delta is up to $50 \%$ of the basic design strength of the beams at lower third of the building. To calibrate the effect of P-Delta two factors must be investigated before incorporating P-Delta effect into design, which are: structural ductility demand and ground motion period [5]. For this purpose, Malaysian Earthquake ground motion has been used in this study. Malaysian Earthquake ground motion is considered as low to medium seismicity region [6]. However, there are many limitations which might be implemented in order to consider the effect of P-Delta such as: the total story drift of three one-fourth scale reinforced concrete frame structure models exceeds 1/85 rad [7]. Yen (1993) introduced a method for direct analysis of nonlinear behavior of slender beam-columns based on the strain control techniques. A strain control technique was developed to obtain the updated flexural stiffness directly for lateral deflection estimation [8]. Fenwick et al. (1992) reviewed thousands of inelastic time history analyses on single degree of freedom to examine the effect of P-Delta. It is shown that the influence factors are ductility, ground motion duration, level of damping, and period of structure [9].

Few experimental research works have been conducted on the effect of P-Delta. Consequently, it is very difficult to show the effect of P-Delta accurately and efficiently. In particular, lack of literature regarding the influence of P-Delta in relation to structural height was another barrier in order to identify its impact on P-Delta effect. The main aim of this paper is to determine to what extent height variation of building is adverse to building design.

\section{Finite element modeling}

Ten different concrete and steel models (different height) were created by using finite element software. Two methods of seismic analysis were used, which were nonlinear dynamic procedure (NDP) and nonlinear static procedure (time history analysis and pushover analysis respectively). All models were subjected to Malaysian earthquake excitation. Furthermore, the performance level of plastic hinges was examined to show the impact of P-Delta. The models were analyzed and simulated according to ASCE 7-05 [10], and FEMA [11].

* Corresponding author: sardasht.sardar@komar.edu.iq 


\section{Nonlinear dynamic procedure (time history analysis)}

At least three ground motions should be used to compute the acceptance spectra because the calculated response is very sensitive. In addition, mathematical model for time history analysis are identical to those of spectra response analysis. Consequently more than one ground motion has been used. The time history analysis allows seeing the response of the structure in time dependent history (see Fig.1).

\section{Nonlinear static (pushover analysis)}

procedure

Impulse force was applied to the highest joint A1 (see Fig. 2) of each model. The steps of the increased loading are due to the characteristics of structural element. At the beginning, plastic hinges happens. As the applying force continues, the number of plastic hinge occurrence increases until the last stage of plastic hinge performance occurs. P-Delta effect was included since pushover analysis is an indicator of structural health and safety.

\section{Concrete models}

Five concrete models have been developed with different heights. The main variable parameter was the number of story levels. The models were subjected to First, Malaysian ground acceleration, and Second, Pushover force. The physical properties of all concrete models were same. Columns and beam properties have been shown in Table 1.

Table 1. Concrete section properties

\begin{tabular}{|c|c|c|}
\hline Sections & Size $(\mathrm{mm})$ & $\begin{array}{c}\text { Steel } \\
\text { bars \#9 }\end{array}$ \\
\hline \multicolumn{2}{|c|}{ All beams are $600 \times 400$ reinforced with $6 \# 9$} \\
\hline Column B \& G & $600 \times 500$ & 6 bars \\
\hline $\begin{array}{c}\text { Column } 1 \text { st } \\
\text { and the rest }\end{array}$ & $600 \times 500$ & 6 bars \\
\hline
\end{tabular}

\subsection{Time history analysis}

The result of Non-linear Dynamic Procedure (NDP) can be divided into five subdivisions to obtain the result of each model and interpret the effect of P-Delta on amplitude. For all models, structural response was examined by applying Malaysian ground motion once with P-Delta and another without P-Delta to measure its effect on structural response. Fig. 3 shows time history displacement of FE model of 5, 10, 15, 20 story concrete models. Time history displacement of 25 story model was not following the same pattern; therefore it has been excluded from almost all the analyses.

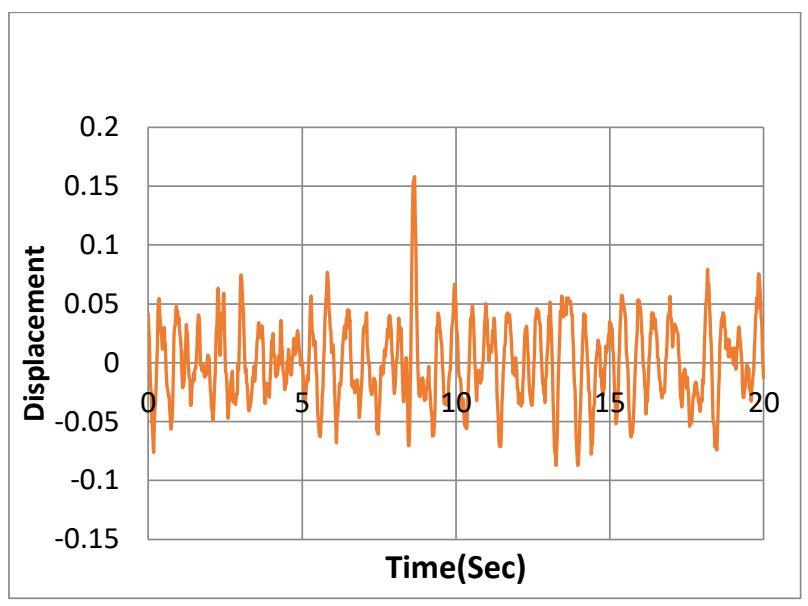

Fig. 1. Malaysian time history

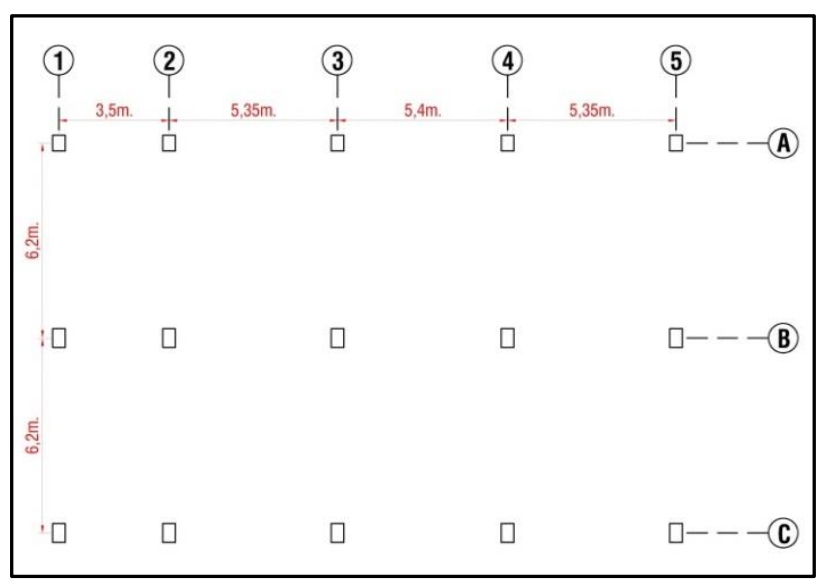

Fig. 2. Site Plan of the mode

\subsection{Peak amplitude}

FE model analysis showed that including P-Delta effect was very severing for 5 story model. The peak amplitude escalated to $68.28 \mathrm{~mm}$ from $39.27 \mathrm{~mm}$ (see Fig. $4 \mathrm{a}$ ). It can be seen the amplitude variation was doubled due to the contribution of P-Delta effect. As the height of the building increased, the effect of P-Delta decreased. For 10 story concrete model peak amplitude changed to $100 \mathrm{~mm}$. The effect of P-Delta was 33\%. It was observed that due to weight height ratio (see Fig. 4 a, and b), the influence of P-Delta has been reduced. As the number of story levels increased, the peak amplitude increased as well. The peak amplitude of 15 and 20 story concrete models became $128 \mathrm{~mm}$, and $251 \mathrm{~mm}$, respectively.

The results were shown that P-Delta effect contribution leads to increase in the amplitude by $30 \%$ and 19.92\%, respectively (see Fig.4 c, and d). The amplitude value of 25 story concrete models was dropped to less than $185 \mathrm{~mm}$. This is mainly due to catastrophic failure which could be observed from the mode shape (see Fig.5). 

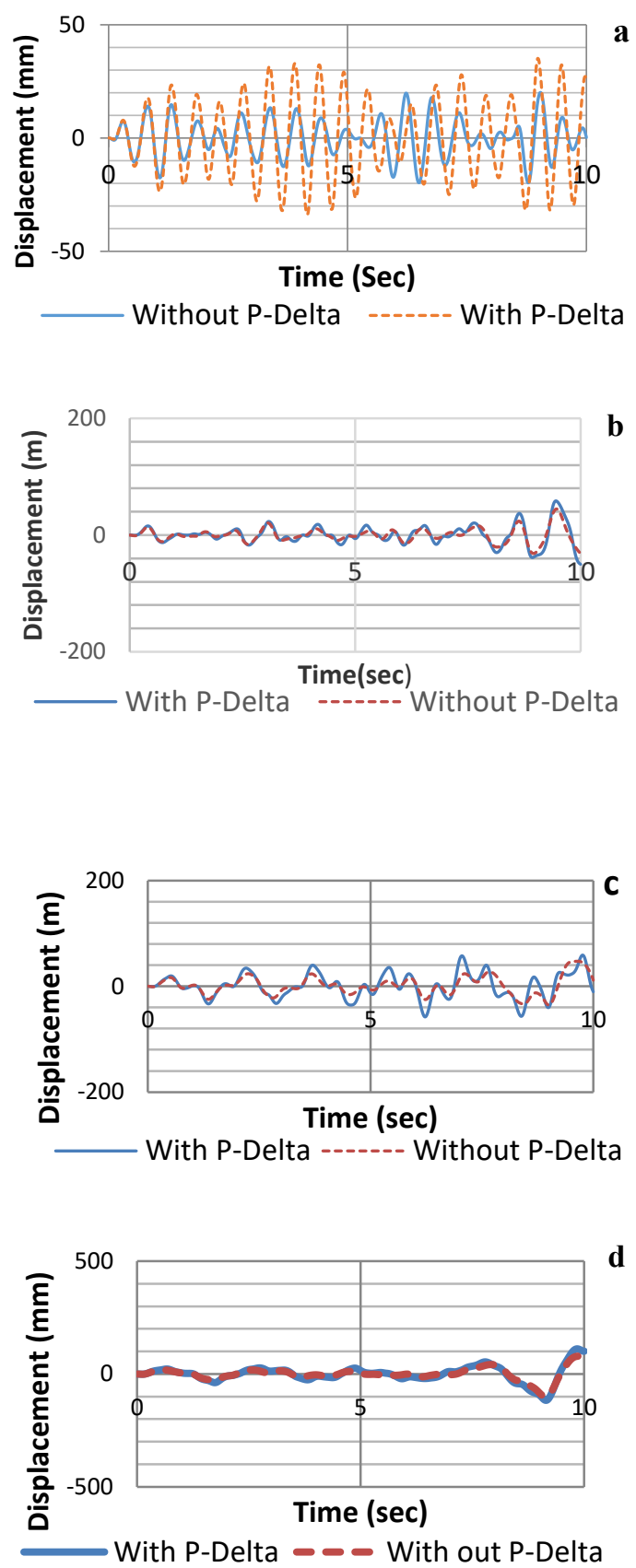

Fig.3. Time History Analysis Displacement; a. 5 story level, b. 10 story level, c. 15 story level, d. 20 story level
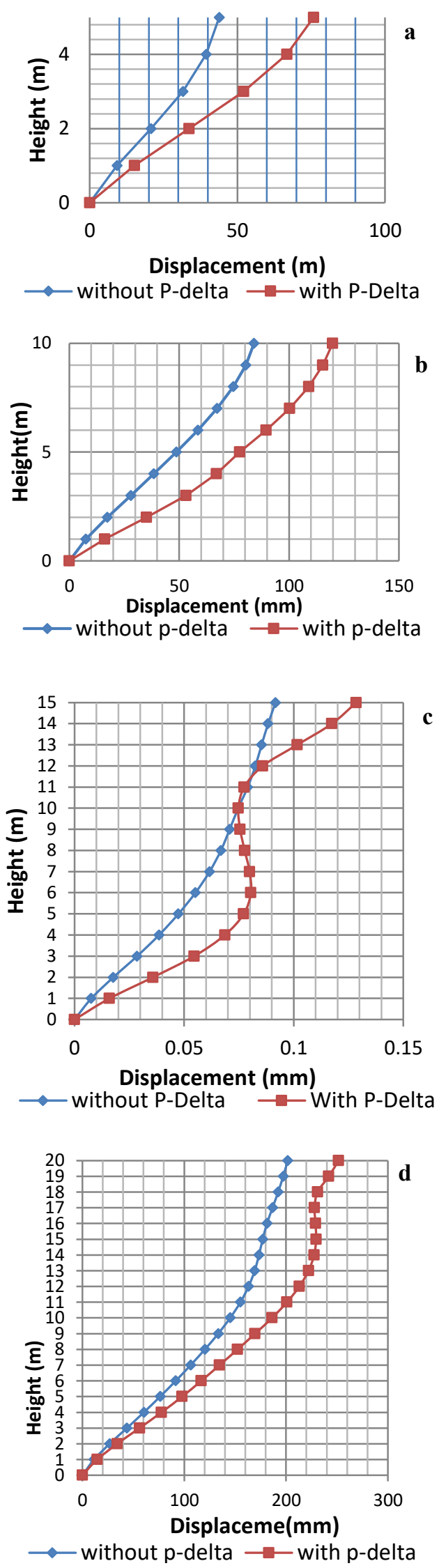

Fig.4. Peak amplitude; a. 5 story level, b. 10 story level, c. 15 story level, d. 20 story level 


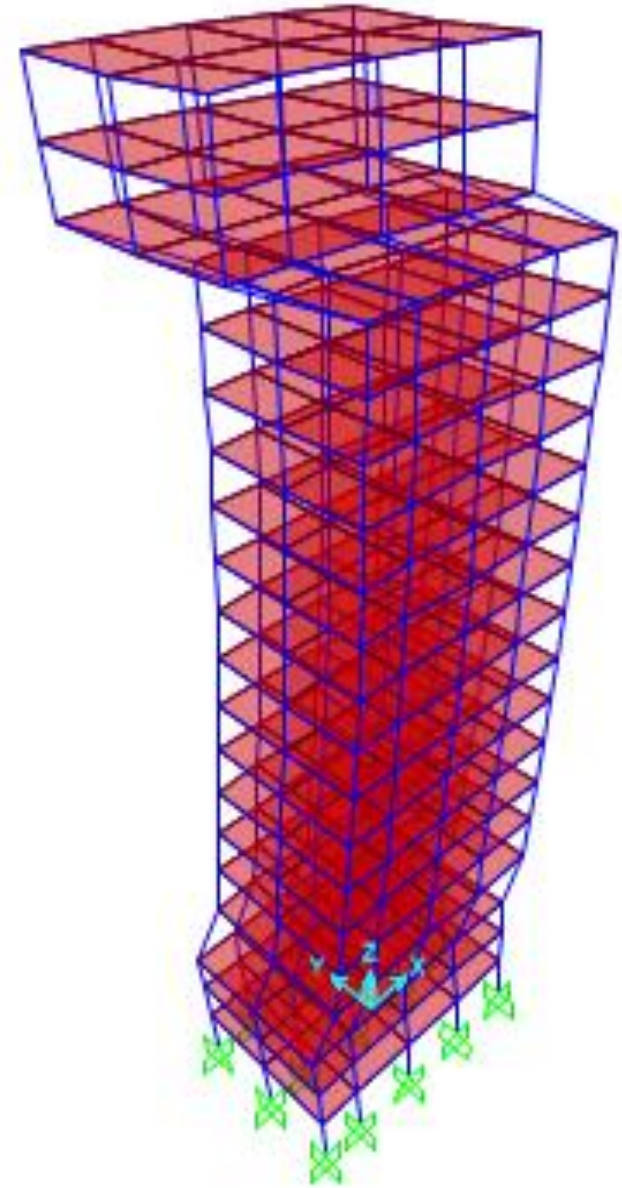

Fig.5. 25 story levels 3D mode shape

\subsection{Pushover analysis}

In this section three different concrete models have been investigated to determine the effect of structural height on P-Delta effect. P-Delta effect contribution resulted in increasing number of plastic hinges occurrence from 0 to 56 for 5 story concrete model (see Fig. 6). The result shows that the effect is sever and should not be overlooked without proper design consideration. Apparently, the amplitude was affected by the influence of P-Delta. The effect of P-Delta leads to increase the amplitude by three times (see Fig.7). Fig. 8 shows the effect of P-Delta on the number of plastic hinge occurrence for 15 story concrete model. The study observed that the number of plastic hinges escalated from 16 to 121. The amplitude was also increased by $39.8 \%$ due to the effect of P-Delta (see Fig.9).
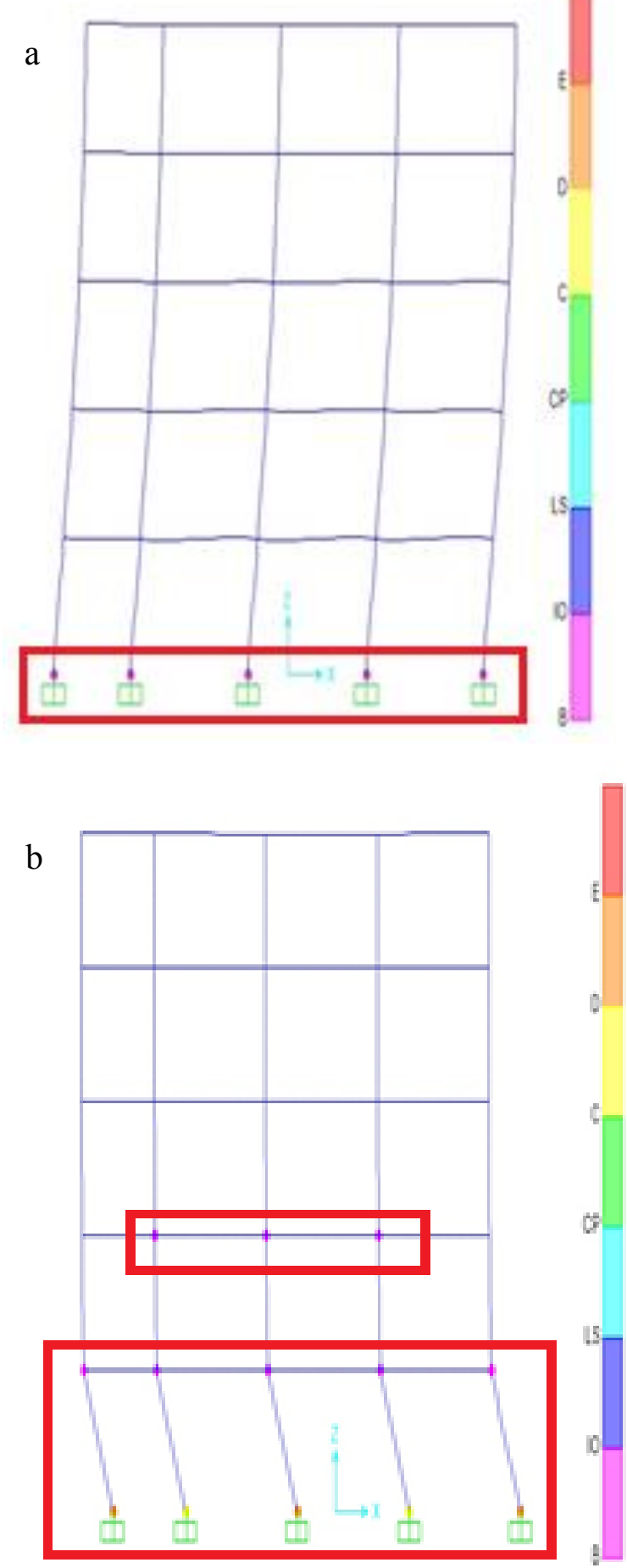

Fig. 6. Deformed shape and Plastic Hinge Occurrence. a. Without P-Delta effect, b. With P-Delta effect 


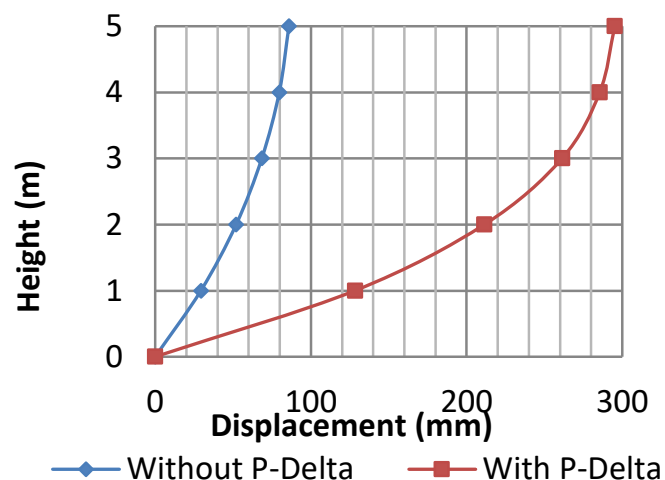

Fig. 7. P-Delta effect on peak amplitude

a

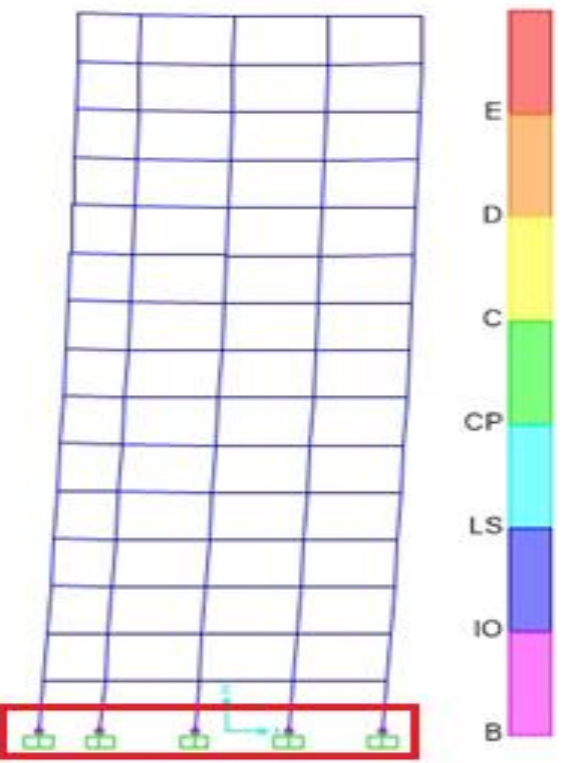

b

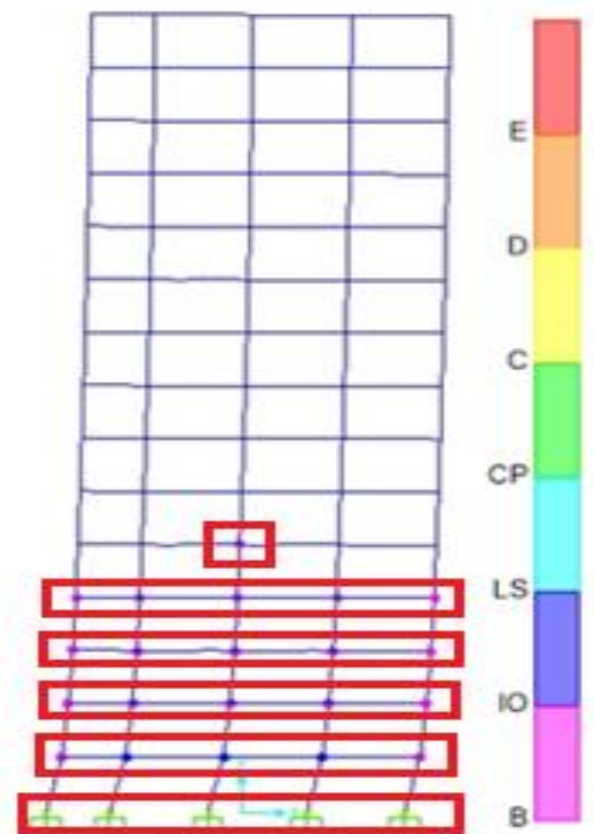

Fig.8. Deformed shape and Plastic Hinge Occurrence. a. Without P-Delta effect, b. With P-Delta effect

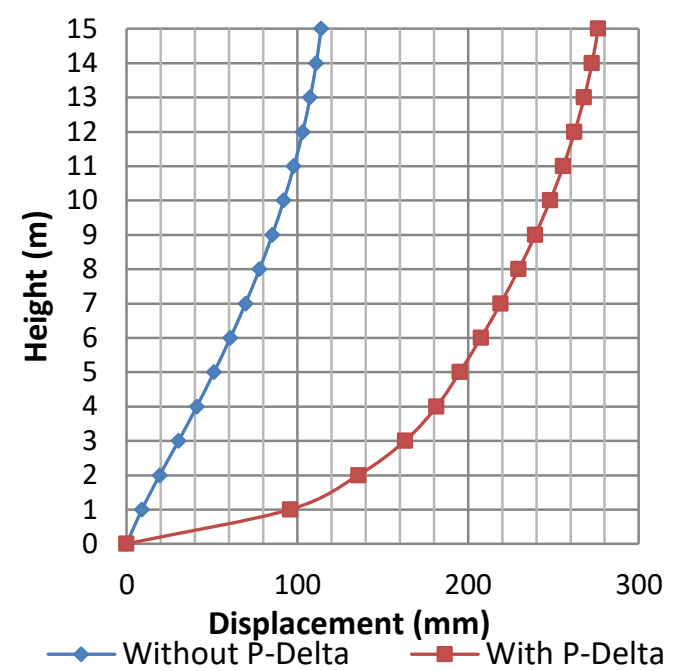

Fig. 9. P-Delta effect on Amplitude

Numbers of plastic hinge happening of 25 story concrete models were increased to 206 from 23 due to the effect of P-Delta (see Fig.10). The amplitude is also affected and it increased to $490 \mathrm{~mm}$ from $345 \mathrm{~mm}$ (see Fig. 11).

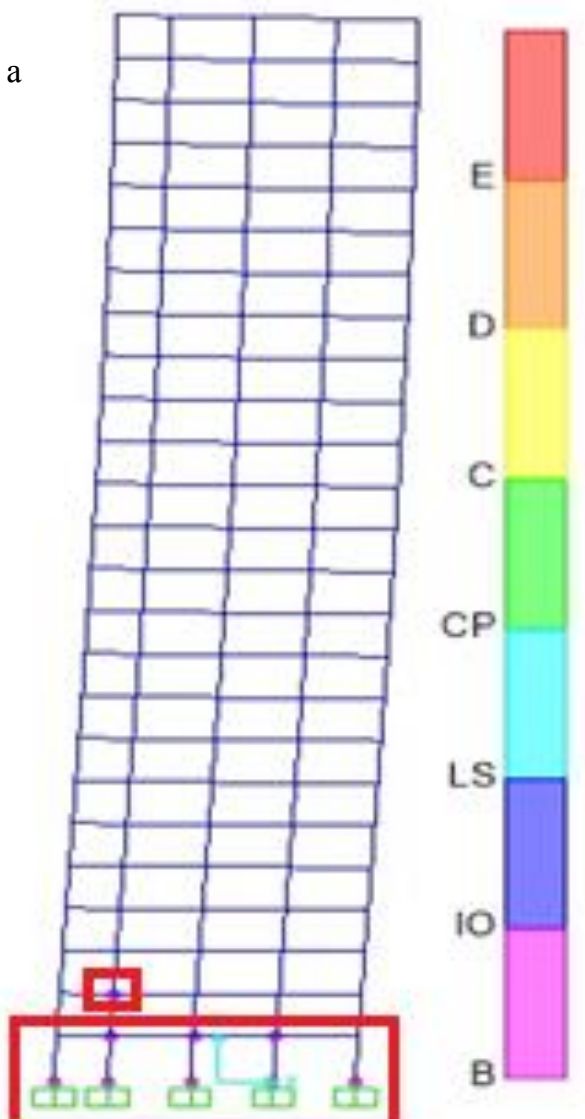


b

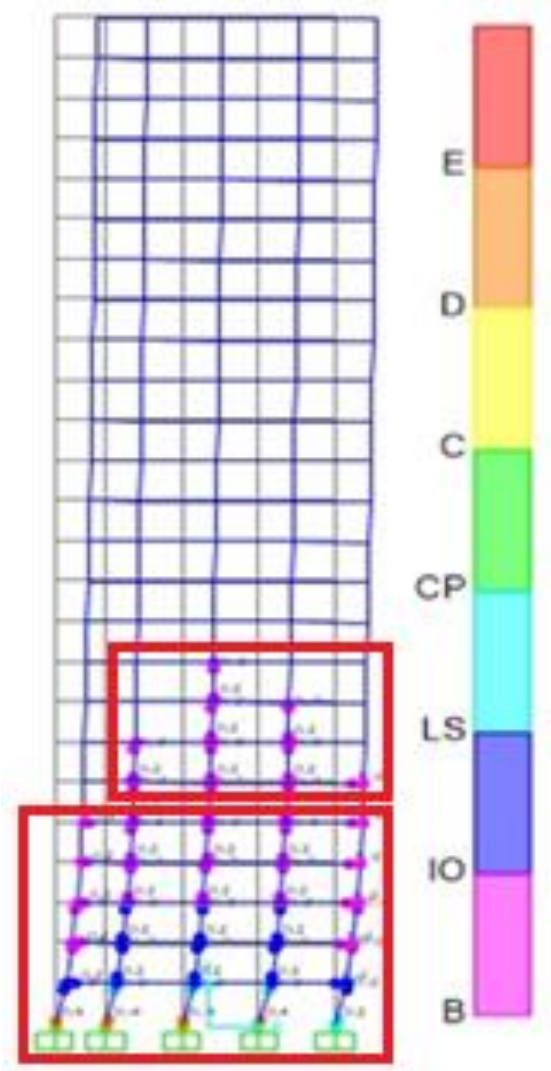

Fig.10. Deformed shape and Plastic Hinge Occurrence. a. Without P-Delta effect, b. With P-Delta effect

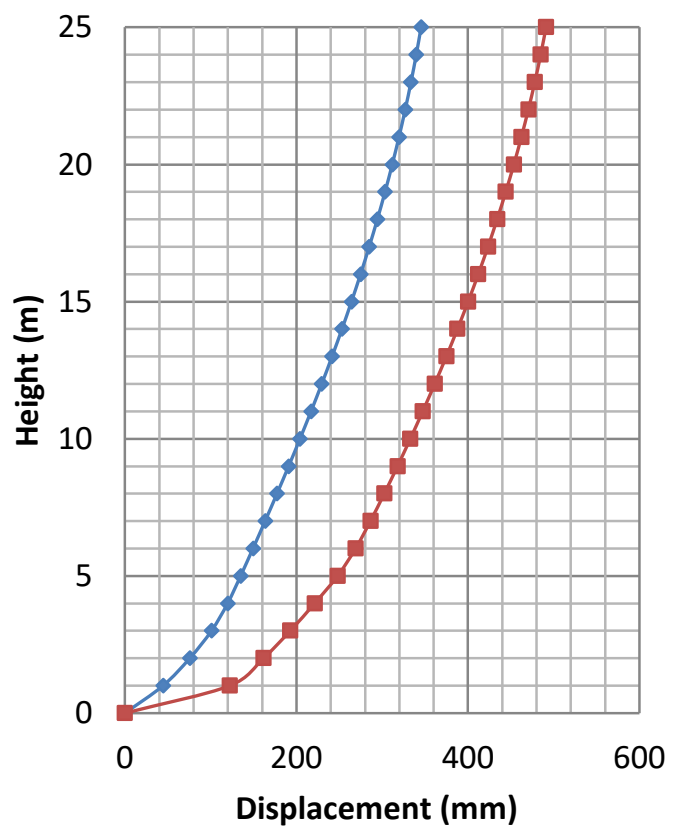

$\because$ Without $\mathrm{p}$-Delta $\quad \longrightarrow$ With $\mathrm{p}$-Delta

Fig. 11. P-Delta effect on Amplitude

\section{Steel models}

Five steel models have been developed with different heights. The main variable parameter was the height. The steel models were subjected to First, Malaysian ground acceleration, and Second, Pushover force. The physical properties of all steel models were same. Both beams and columns sections have different section properties as shown in Table 2.

Table 2. Steel section properties

\begin{tabular}{lll}
\hline Sections & Type & Size \\
\hline Beams & W & $533 \times 210$ \\
Columns & W & $533 \times 310$ \\
\hline
\end{tabular}

\subsection{Time history analysis}

Non-linear Dynamic Procedure (NDP) has been applied on all the steel models. It was indicated that the time history displacement for all different height models was following the same pattern. The result of each model has been determined and shown briefly to present the structural response. Fig.12 shows time history displacement of all five steel models.

\subsection{Peak amplitude}

It's indicated that peak amplitude for 5 story steel model was higher than 5 story concrete models. For 5 story steel structures the amplitude is $40.5 \mathrm{~mm}$, while contributing P-Delta effect to the analysis leads to increase the amplitude to $69.8 \mathrm{~mm}$ (see Fig. 13 a). The effect of P-Delta on the amplitude for 10 story steel model was significantly low (4\%) (see Fig.13 b). Eventually, the effect was increased to $21 \%$ for 15 story steel model. Furthermore, the peak amplitude was raised to $51.7 \%$ which was increased to $317 \mathrm{~mm}$ from $164.1 \mathrm{~mm}$ (see Fig.13 c and d). On the other hand, 25 story steel model has failed to provide logical result due to paramount collapse (see Fig.14). The same failure pattern for 25 story concrete model can be observed.

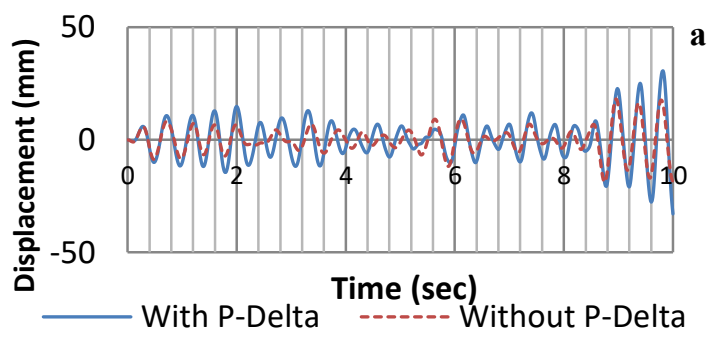



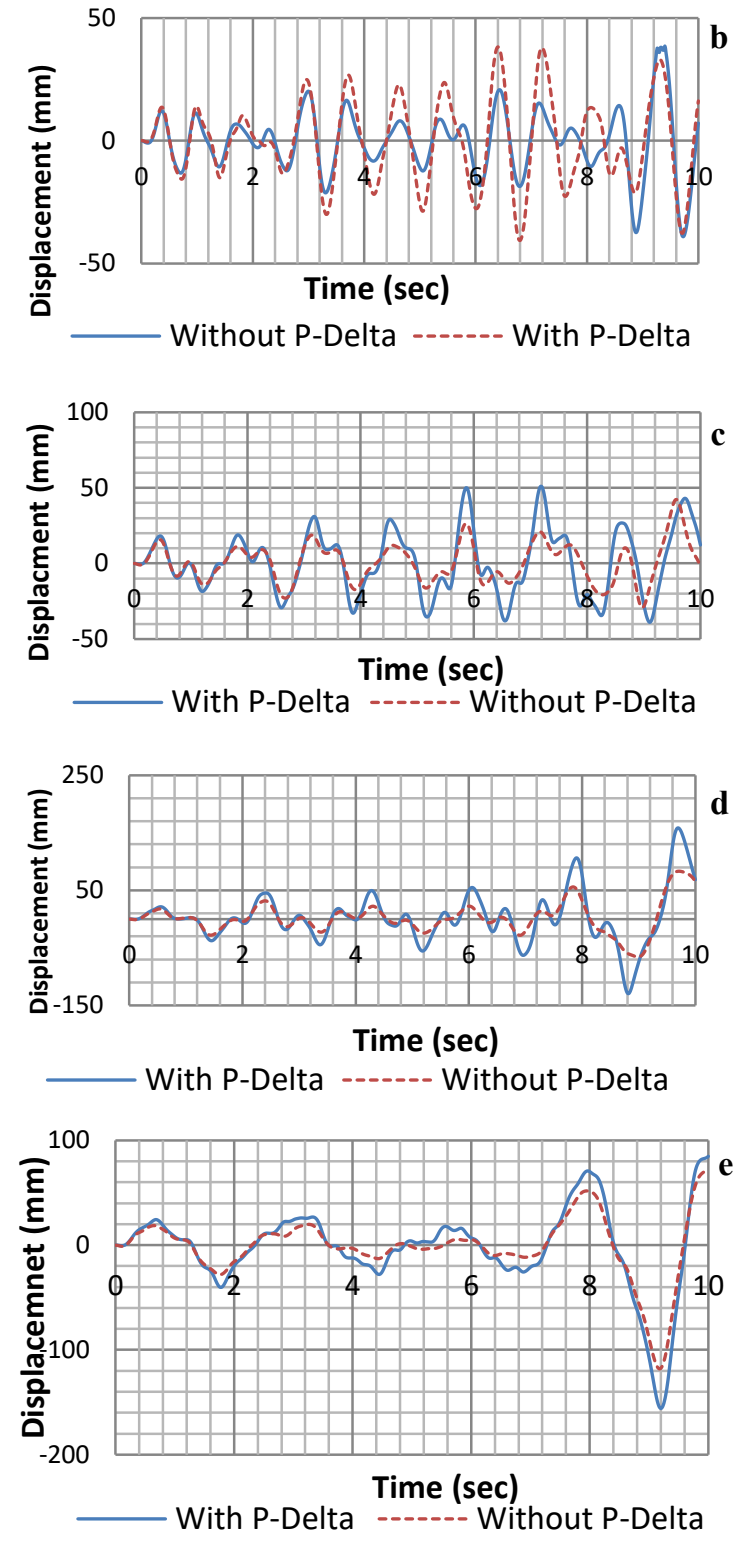

Fig. 12. Time History Analysis Displacement; a. 5 story level, b. 10 story level, c. 15 story level, d. 20 story level, e. 25 story level

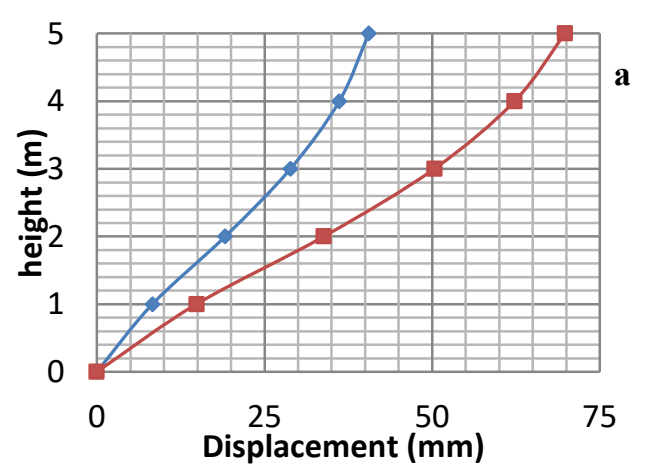

$\longrightarrow$ without $\mathrm{p}$-delta $\longrightarrow$ with p-delta

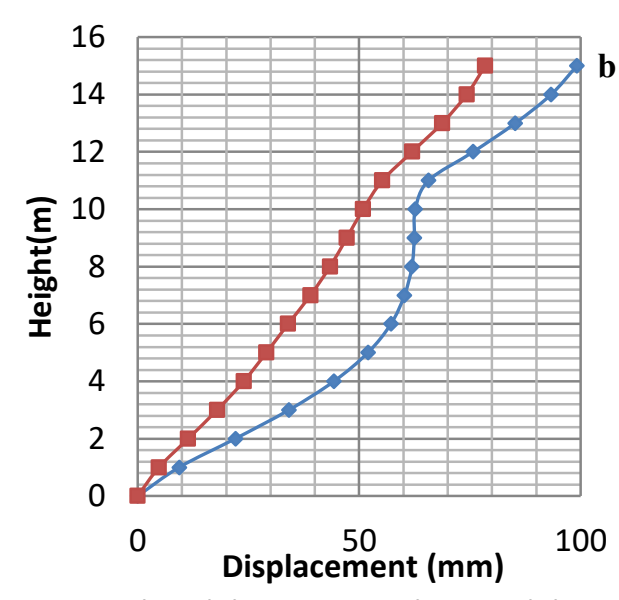

$\multimap$ with p-delta $\longrightarrow$ without p-delta
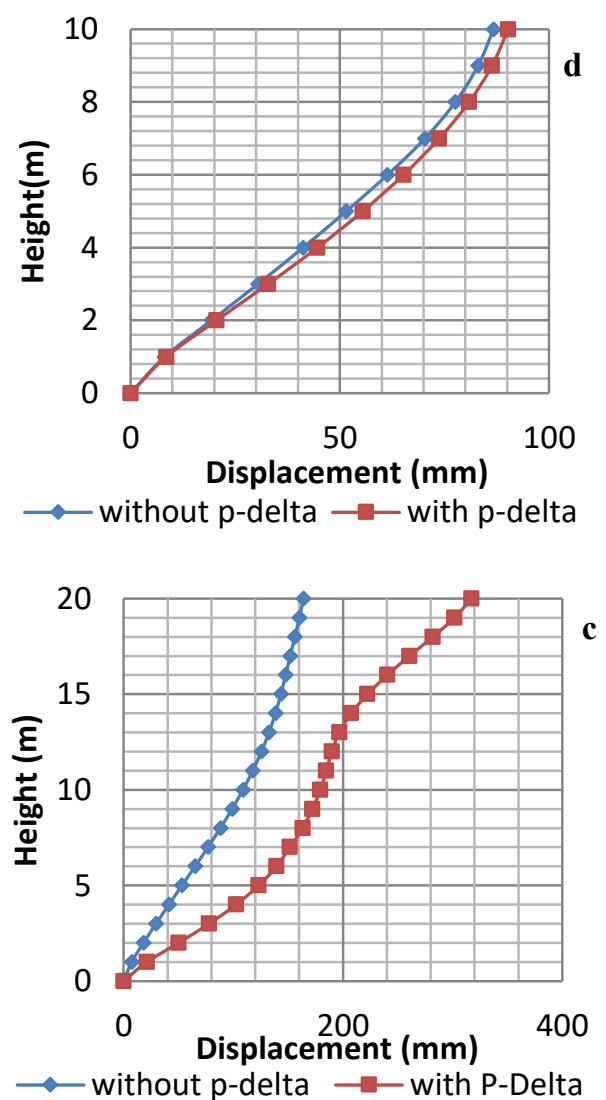

Fig.13. Peak amplitude; a. 5 story level, b. 10 story level, c. 15 story level, d. 20 story level 


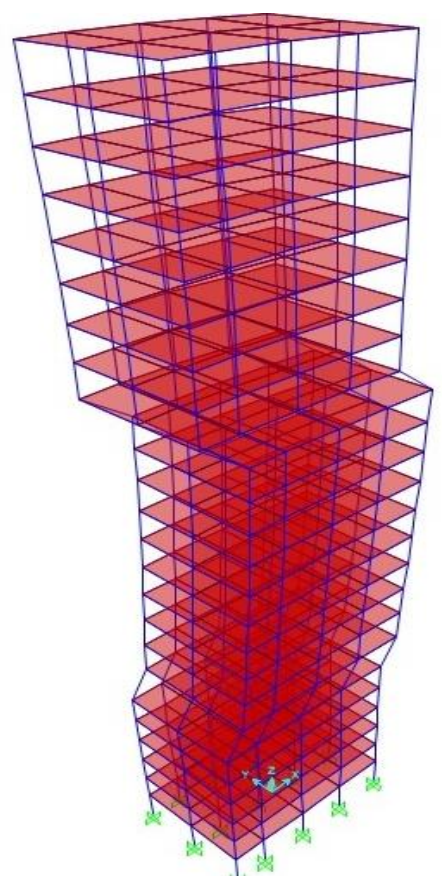

Fig. 14. 25 Story steel model which is failed due to excessive height

\subsection{Pushover analysis}

Ignoring P-Delta effect resulted in reducing 6 plastic hinges for 5 story steel model. While for 10 story steel model the difference was increased to 66 plastic hinge occurrence. Further height increment leads to change the performance level of plastic hinge formation from very slight (elastic range) to slight (collapse prevention) according to FEMA-365 description (see Fig.15). Very little changes in the number of plastic hinges occurrence has been observed for 15,20 , and 25 story steel models. It was investigated that the effect of P-Delta was insignificant to the quantity of plastic hinges formation, but plastic hinges performance level moved to beyond strong level (IO-Immediate Occupancy).Fig.16 shows plastic hinge formation distribution throughout the height of 15, 20, and 25 story steel models. $\mathbf{a}$
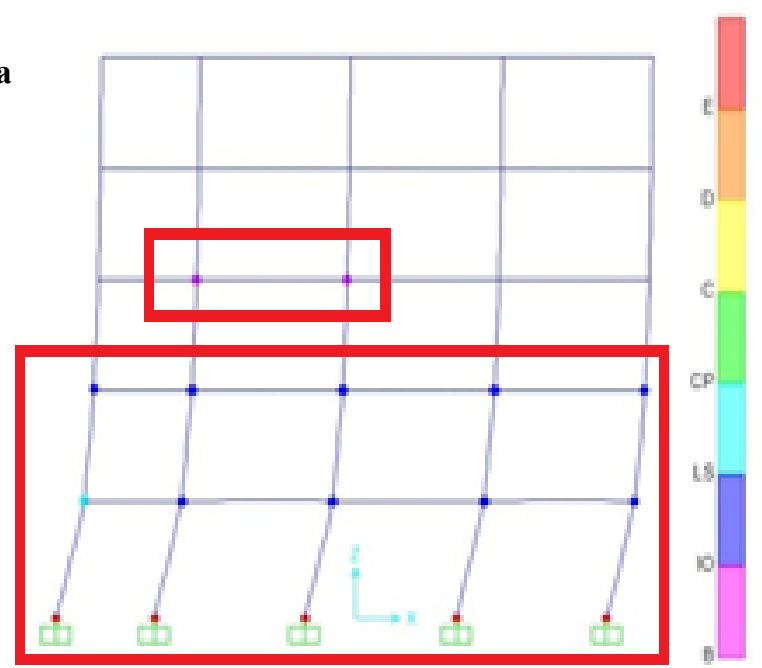

b
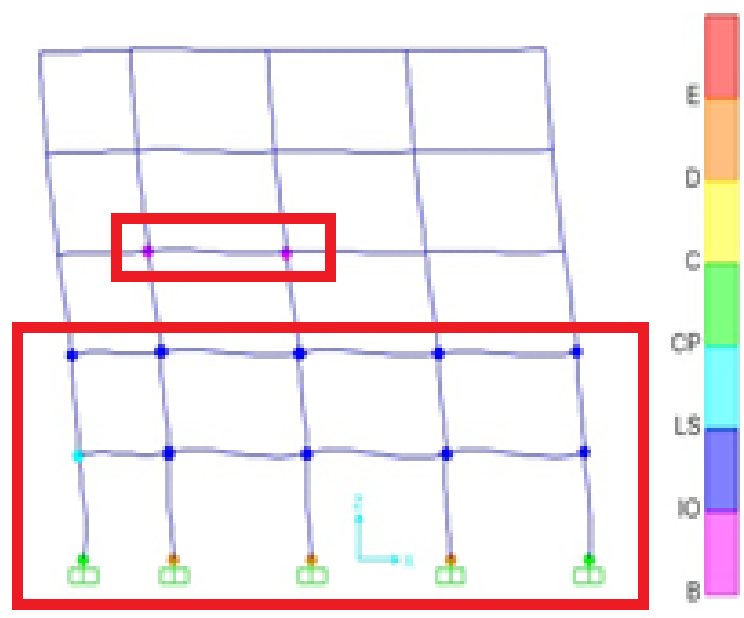

c

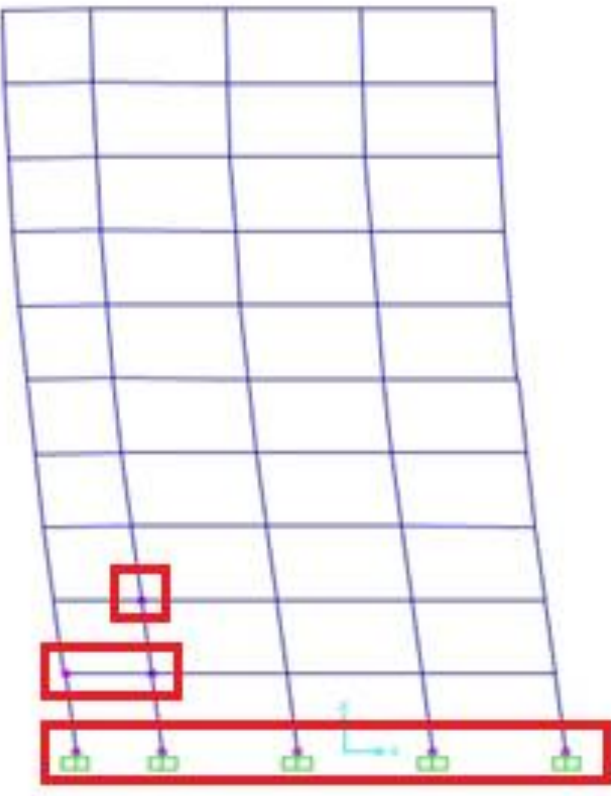



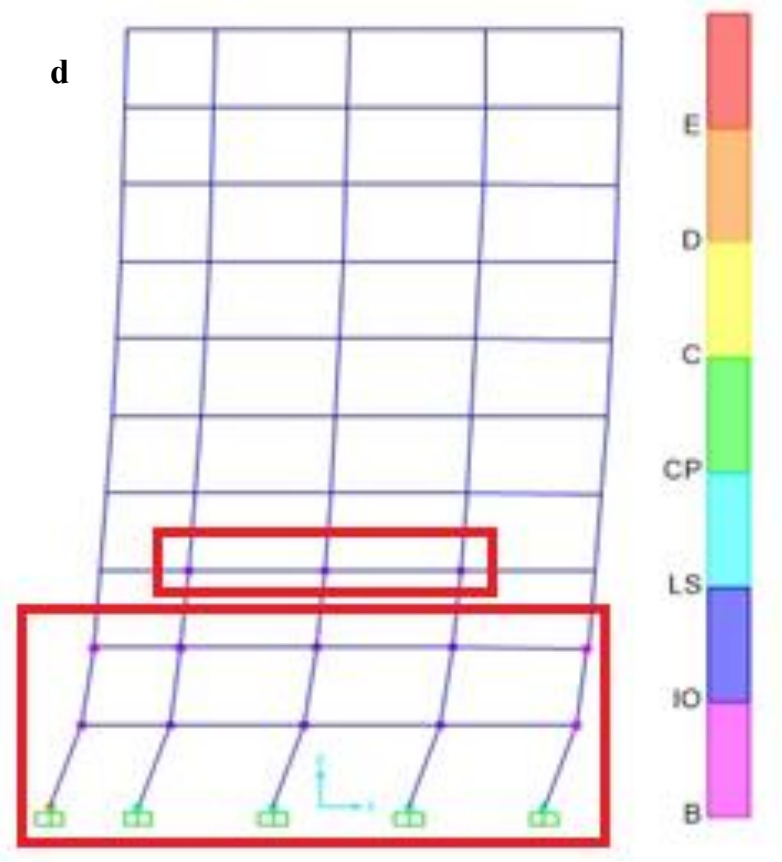

Fig.15. Plastic Hinge Occurrence, a. 5 story steel model without P-Delta, b. 5 story steel model with P-Delta, c. 10 story steel model without P-Delta, d. 10 story steel model with PDelta
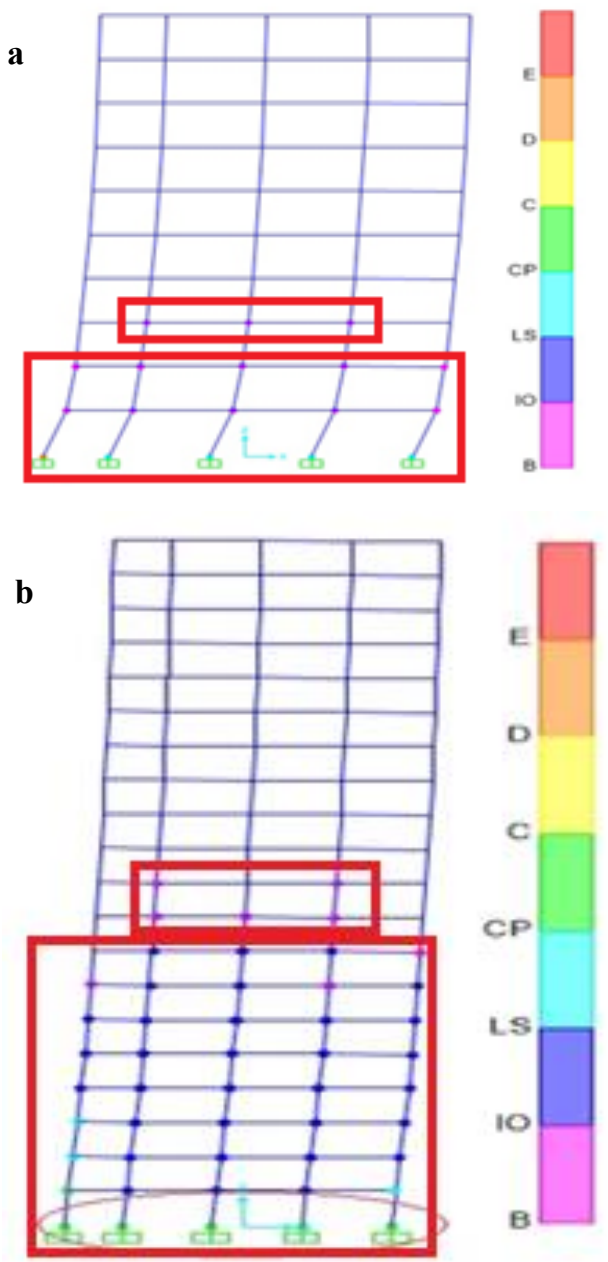

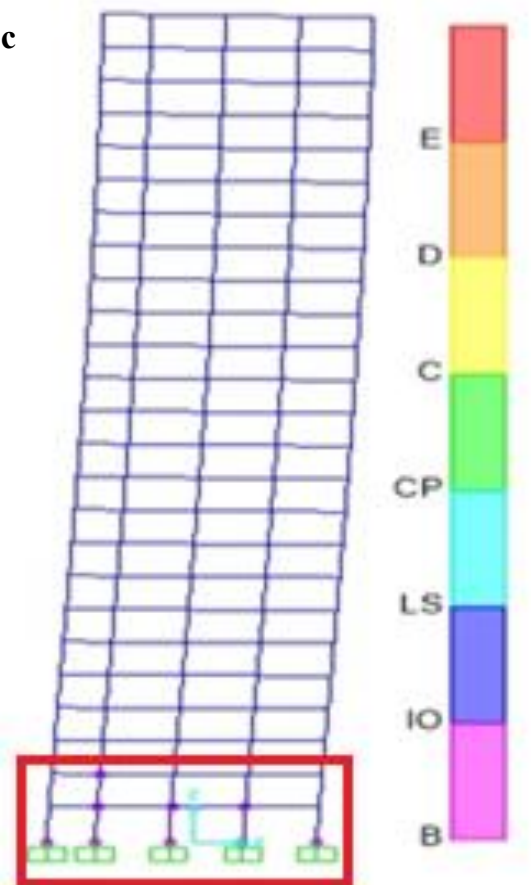

Fig.16. Plastic hinges formation, a. 10 story steel model, b. 15 story steel models, c. 20 story steel mode

Amplitude is one of the parameters which might be affected by P-Delta in pushover analysis. The impact of P-Delta was sever and cannot be overlooked without proper design consideration. For instance, for 5 story steel model the effect of P-Delta leads to increase the amplitude by $60 \mathrm{~mm}$ (see Fig. 17 a). It can be seen that the effect of P-Delta was reduced to $22 \mathrm{~mm}$, when the height of the model increased to 10 story level (see Fig. 17 b). The results showed that further increasing the number of story levels did not affect the amplitude. This might be due to the performance level of plastic hinges occurrences which was beyond immediate occupancy according to FEMA description.

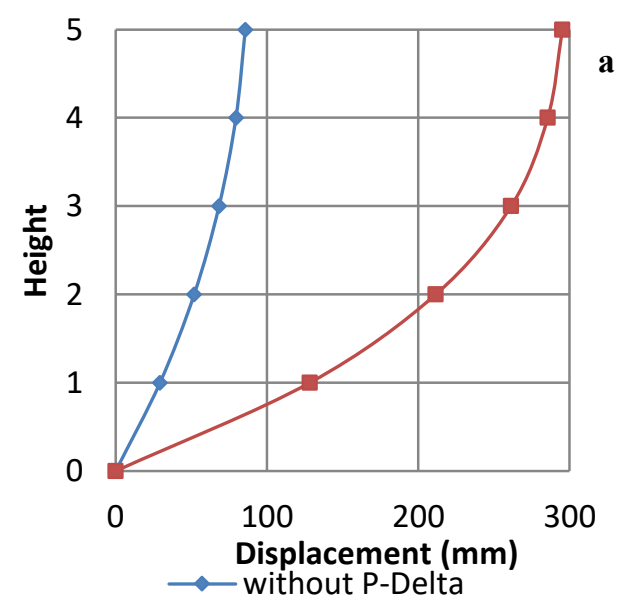




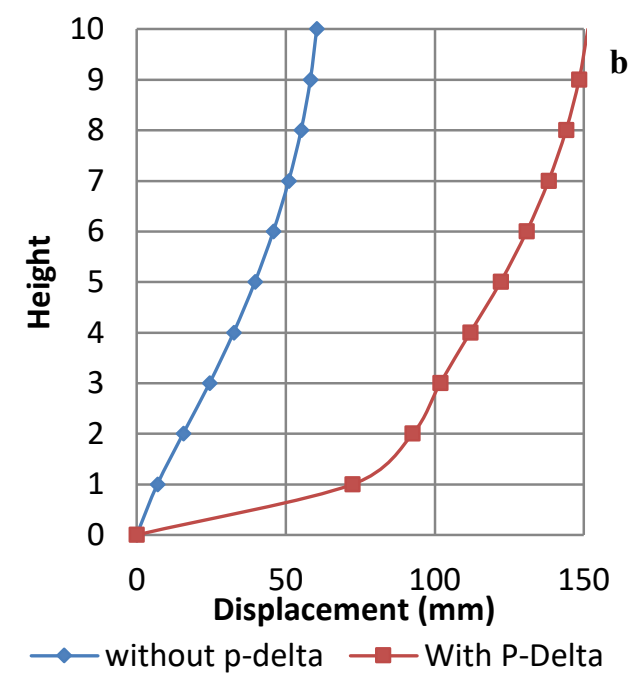

Fig.17. Peak amplitude, a. 5 story steel model, b. 10 story steel model,

\section{Results and comparison}

The effect of P-Delta on the amplitude of 5 story steel model and 5 story concrete model was $42 \%$, while the effect of P-Delta on the amplitude of 10 story steel and concrete models were $4.4 \%$, and $33 \%$, respectively. The effect of P-Delta for 15 and 20 story concrete models were decreased to $30 \%$, and $20 \%$, respectively. On the other hand, time history results shown that the effect of P-Delta in 15 and 20 story steel models were $21 \%$, and $52 \%$, respectively. It was observed that the effect of PDelta due to the height variation of steel structures is more effective than the concrete structures. Structural weight has a major contribution to the effectiveness of PDelta. In fact, concrete models weight were greater than the weight of steel models, as a result, P-Delta influence became lesser for concrete models. Ultimately, 25 steel and concrete models failed to give rational results regards the effect of P-Delta. This was mainly due to calamities failure of the structure. P-Delta effect had a very clear impact on the quantity and performance level of plastic hinges formation. For 5, 10, 15, 20, and 25 story concrete models the effect of P-Delta were $70 \%$, $60 \%, 59 \%, 46 \%$, and $30 \%$, respectively. It was indicated that the P-Delta effect became lesser for higher story levels. Again the reason for this is the height weight ratio. Steel models recorded different outcomes. The height increment is too sever on the quantity of plastic hinges occurrence of steel models. The effect of P-Delta on plastic hinges performance was jumped from $6.67 \%$ to $76.7 \%$ when the height increased from 5 to 10 story levels. Further height increment leads to structural elements failure. Therefore, the structural elements of 15,20 , and 25 story steel models failed to carry the excessive loads due to P-Delta effect.

\section{Conclusions}

The second order effect (P-Delta) has been investigated to determine the correlation between structural height and P-Delta effect. Two variables have been included in the analysis, which are; Frist- Number of story levels. Second- Different construction materials have been utilized in the analysis such as steel and concrete. The study utilized two types of analysis, time history analysis and pushover analysis. In both analyses, peak amplitude was a reliable indicator to obtain the effect of P-Delta. Furthermore, plastic hinge formation was found to be a good measurement to observe structural performance. To sum up, the height of the building should be considered as a critical factor in P-Delta effect analysis. The study indicates that steel structures are more sensitive towards the height than concrete structures. In addition, performance level of plastic hinges occurrence in concrete models influenced by the height inversely, while failures have been recorded when the height is increased up to fifteen story levels for steel models.

\section{References}

1. H. Scholz, J. Struct. Eng. 113, 3, 534-545 (Mar. 1987)

2. B. R. Gaiotti, S. Smith, ASCE J. Struct. Eng. 115, 4, 755-770 (1989)

3. B. H. Scholz, 116, 8, 2070-2082 (1991)

4. H.-G. Kwak, J.-K. Kim, Eng. Struct. 29, 11, $3121-$ 3133 (Nov. 2007)

5. B. J. Davidson, R. C. Fenwick, B. T. Chung, Earthquake Engineering ,Tenth World Conference Balkema,Rotterdam, 3847-3852 (1992)

6. S. Engineering, T. Division, Gathering of Views and Opinions on Seismic Investigations in Peninsular Malaysia - Report on the IEM Workshop on Earthquake ( Part 1 ), (October 2011)

7. M. A. A. Mollick, J. Civ. Eng. CE 25, 2, 107-119 (1997)

8. B. J. Y. R. Y. I, ASCE J. Struct. Eng. 119, 3, 871890 (1993)

9. R. C. Fenwick, B. J. Davidson, B. T. Chung, Bull. New Zeal. Natl. Soc. Earthq. Eng. 25, 1, 56-69 (1992)

10. S. a. James R. Harris, ASCE J. Struct. Eng (2010)

11. E. Zeller,FEMA273 (1997) 